\title{
Optimal Management of Asymptomatic Carotid Stenosis: Counterbalancing the Benefits with the Potential Risks
}

\author{
Kosmas I. Paraskevas, ${ }^{\mathrm{a}}$ Dimitri P. Mikhailidis, ${ }^{\mathrm{b}}$ Hediyeh Baradaran, ${ }^{\mathrm{c}}$ Alun H. Davies, ${ }^{\mathrm{d}}$ \\ Hans-Henning Eckstein, ${ }^{\mathrm{e}}$ Gianluca Faggioli, ${ }^{\mathrm{f}}$ Jose Fernandes e Fernandes, ${ }^{\mathrm{g}}$ Ajay Gupta, ${ }^{\mathrm{h}}$ \\ Mateja K. Jezovnik, ${ }^{\mathrm{i}}$ Stavros K. Kakkos, ${ }^{\mathrm{j}}$ Niki Katsiki, ${ }^{ }$M. Eline Kooi, ${ }^{1, \mathrm{~m}}$ Gaetano Lanza, ${ }^{\mathrm{n}}$ \\ Christos D. Liapis, ${ }^{\mathrm{o}}$ Ian M. Loftus, ${ }^{\mathrm{p}}$ Antoine Millon, ${ }^{\mathrm{q}}$ Andrew N. Nicolaides, ${ }^{\mathrm{r}}$ Pavel Poredos, ${ }^{\mathrm{s}}$ \\ Rodolfo Pini, ${ }^{\mathrm{f}}$ Jean-Baptiste Ricco, ${ }^{\mathrm{t}}$ Tatjana Rundek, ${ }^{\mathrm{u}}$ Luca Saba, ${ }^{\mathrm{v}}$ Francesco Spinelli, ${ }^{\mathrm{w}}$ Francesco Stilo, ${ }^{\mathrm{w}}$ \\ Sherif Sultan, ${ }^{\mathrm{x}}$ Clark J. Zeebregts, ${ }^{\mathrm{y}}$ Seemant Chaturvedi ${ }^{\mathrm{z}}$

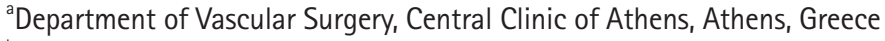 \\ ${ }^{b}$ Department of Clinical Biochemistry, Royal Free Hospital Campus, University College London Medical School, University College London (UCL), \\ London, UK \\ 'Department of Radiology, University of Utah, Salt Lake City, UT, USA. \\ ${ }^{\mathrm{d}}$ Section of Vascular Surgery, Imperial College \& Imperial Healthcare NHS Trust, London, UK \\ eDepartment of Vascular and Endovascular Surgery, University Hospital rechts der Isar, Technical University of Munich, Munich, Germany \\ 'Vascular Surgery, University of Bologna "Alma Mater Studiorum", S. Orsola-Malpighi Polyclinic, Bologna, Italy \\ ${ }^{9}$ Department of Vascular Surgery, Lisbon Academic Medical Center, University of Lisbon, Lisbon, Portugal \\ ${ }^{\text {h}}$ Department of Radiology, Weill Cornell Medicine, New York, NY, USA \\ 'Department of Advanced Cardiopulmonary Therapies and Transplantation, The University of Texas Health Science Centre at Houston, Houston, TX, USA \\ 'Department of Vascular Surgery, University of Patras Medical School, Patras, Greece \\ ${ }^{k}$ First Department of Internal Medicine, AHEPA University Hospital, Thessaloniki, Greece \\ 'CARIM School for Cardiovascular Diseases, Maastricht University, Maastricht, The Netherlands \\ mepartment of Radiology and Nuclear Medicine, Maastricht University Medical Center, Maastricht, The Netherlands \\ "Vascular Surgery Department, IRCSS MultiMedica Hospital, Castellanza, Italy \\ ${ }^{\circ}$ Athens Vascular Research Center, Athens, Greece

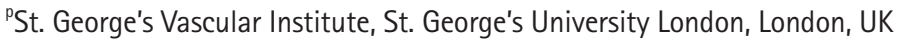 \\ ${ }^{9}$ Department of Vascular and Endovascular Surgery, Louis Pradel Hospital, Hospices Civils de Lyon, Lyon, France \\ 'Department of Surgery, University of Nicosia Medical School, Nicosia, Cyprus

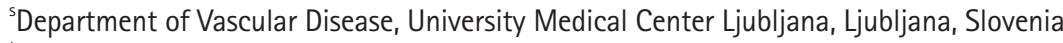 \\ tDepartment of Clinical Research, University of Poitiers, CHU de Poitiers, Poitiers, France \\ uDepartment of Neurology, Miller School of Medicine, University of Miami, Miami, FL, USA \\ ${ }^{v}$ Department of Radiology, University Hospital Center of Cagliari, Cagliari, Italy \\ "Vascular Surgery Division, Campus Bio-Medico University of Rome, Rome, Italy \\ ${ }^{x}$ Western Vascular Institute, Department of Vascular and Endovascular Surgery, University Hospital Galway, National University of Ireland, \\ Galway, Ireland \\ 'Division of Vascular Surgery, Department of Surgery, University Medical Center Groningen, University of Groningen, Groningen, The Netherlands \\ ${ }^{2}$ Department of Neurology \& Stroke Program, University of Maryland School of Medicine, Baltimore, MD, USA
}

\section{Dear Sir:}

We thank Dr. Abbott for her interest in our work. ${ }^{1}$

Dr. Abbott supports that best medical treatment (BMT) has improved considerably over the last 3 to 4 decades since the landmark randomized controlled trials (RCTs) were performed. However, surgical outcomes with carotid endarterectomy (CEA) have similarly improved over the same period, with some centers reporting perioperative stroke rates with CEA as low as $0.3 \%{ }^{2}$ to $0.9 \%{ }^{3}$ for asymptomatic carotid stenosis (ACS) pa- 
tients. It is therefore inappropriate to compare the event rates with current BMT alone and those with CEA in the past landmark RCTs.

Although there is no level I evidence from contemporary RCTs comparing current BMT alone versus CEA plus BMT, Dr. Abbott supports that all ACS patients should be managed with current BMT alone and that no ACS patient should be offered a carotid intervention. Dr. Abbott's view that all ACS patients should be managed with current BMT alone contradicts her introductory argument that "the authors should have gone further and concluded that such management should be individualized." Furthermore, some ACS patients may not be satisfied with being managed solely with BMT. For example, the second Stent Protected Angioplasty vs Carotid Endarterectomy (SPACE-2) trial, which planned to randomize patients to CEA, carotid artery stenting (CAS) or BMT, had to be abandoned due to slow recruitment. ${ }^{4}$ Patients were not satisfied with being randomized to BMT alone, especially since all three study arms received BMT anyway. ${ }^{4}$

The 2017 European Society for Vascular Surgery (ESVS) guidelines for the management of patients with carotid artery stenosis recommended that in "average surgical risk" patients with a 60\% to 99\% ACS, CEA should (Class Ila; Level of Evidence: B) or CAS may be considered (Class Ilb; Level of Evidence: $B$ ) in the presence of one or more clinical/imaging characteristics that may be associated with an increased risk of late ipsilateral stroke, provided documented perioperative stroke/ death rates are $<3 \%$ and patient life expectancy is $>5$ years. ${ }^{5}$ These clinical/imaging characteristics included silent embolic infarcts on brain computed tomography/magnetic resonance imaging (MRI), progression in the severity of ACS, a history of contralateral transient ischemic attack/stroke, microemboli detection on transcranial Doppler, the presence of intraplaque hemorrhage or plaque ulceration on MRI, reduced cerebrovascular reserve, a large plaque area $\left(>40 \mathrm{~mm}^{2}\right)$ on ultrasound longitudinal images and plaque echolucency as shown by a low gray scale median $(<30)$ and presence of a large $\left(>8 \mathrm{~mm}^{2}\right)$ juxtaluminal hypoechoic area after image normalization of $\mathrm{Du}$ plex ultrasound images. ${ }^{5}$

A recent systematic review and meta-analysis (64 studies; 20,751 patients) showed that the pooled prevalence of highrisk carotid plaque features was 26.5\% (95\% confidence interval [Cl], $22.9 \%$ to $30.3 \%$ ) in ACS patients. ${ }^{6}$ Over a mean follow-up period of 2.8 years (range, 0.7 to 6.5 ), the incidence of ipsilateral ischemic cerebrovascular events was $3.2(95 \% \mathrm{Cl}$, 2.2 to 4.3 ) events per 100 person-years in the overall population. ${ }^{6}$ However, this incidence was three times higher in ACS patients with high-risk features compared with those without high-risk features (4.3 vs. 1.2 events per 100-person years, respectively; odds ratio, 3.0; 95\% $\mathrm{Cl}, 2.1$ to 4.3$)^{6}{ }^{6}$ As the authors stated, "a key finding of this meta-analysis was that the risk of ipsilateral ischemic events among the overall population of ACS patients (3.2\%) and among the subsets of patients with high-risk plaque features (4.3\%) and without high-risk plaque features (1.2\%) is greater than the commonly accepted rate of $1 \% .^{\prime \prime}$

Regarding the management of female patients with ACS, we have already discussed that an expert committee undersigning a multidisciplinary consensus document recognized that the landmark RCTs were not powered to assess outcomes specifically for women, because they were largely under-represented in all these RCTs. ${ }^{7}$ Nevertheless, they concluded that "there is currently limited evidence to consider BMT alone as the best choice for women with severe ACS." ${ }^{\text {"7 }}$ A strong recommendation for CEA was provided for women with 60\% to $99 \%$ ACS for reduction of long-term risk of stroke, provided the patient has a 5- to 10-year life-expectancy and perioperative stroke/death rates are $\leq 2.0 \%$ (Grade 1, Level of Evidence B). ${ }^{7}$ In contrast, for older and more frail female patients, BMT alone may be preferable.

As we support in our manuscript, ${ }^{1}$ the management of ACS patients needs to be individualized, taking into consideration, among other factors, patient age, comorbidities, sex, needs, and preferences. We do not agree with the conclusion that BMT alone is adequate for the management of all ACS patients regardless of any criteria, ignoring international guidelines and expert consensus documents which provide different recommendations, ${ }_{1}^{4,7}$ and without any Level I Evidence. The optimal management of ACS remains the subject of debate; ${ }^{8}$ however, a "one-size-fits-all" approach based on the results of selected and underpowered population studies, often including patients with moderate ACS is inappropriate and potentially denies patients access to additional treatment options that could further minimize future stroke risk. The decision to offer conservative or invasive treatment in individual ACS patients is a much more complicated issue than simply assigning everyone to BMT alone and assuming that patient adherence, response to treatment and individual patient needs/expectations are identical for all patients.

The 2022 Society for Vascular Surgery clinical practice guidelines for the management of extracranial cerebrovascular disease provided a strong recommendation for CEA+BMT over BMT alone for low-surgical risk patients with $>70 \%$ ACS (Level of Recommendation: Grade I [Strong]; Quality of Evidence: B [Moderate]). ${ }^{9}$ Although it is essential that all ACS patients should be placed on BMT, emerging evidence suggests that pa- 
tients with severe (80\% to $99 \%$ ) ACS are at high stroke risk with BMT alone and should therefore be considered for a prophylactic carotid procedure to reduce the risk of a future cerebrovascular event. ${ }^{10}$

\section{References}

1. Paraskevas $\mathrm{KI}$, Mikhailidis DP, Baradaran $\mathrm{H}$, Davies AH, Eckstein $\mathrm{HH}$, Faggioli $\mathrm{G}$, et al. Management of patients with asymptomatic carotid stenosis may need to be individualized: a multidisciplinary call for action. J Stroke 2021;23:202-212.

2. Aro $E_{1}$ ljäs $P$, Vikatmaa $L$, Soinne $L$, Sund $R$, Venermo $M$, et al. The efficacy of carotid surgery by subgroups: the concept of stroke prevention potential. Eur J Vasc Endovasc Surg 2019; 58:5-12.

3. Vikatmaa $P$, Mitchell $D$, Jensen $L P$, Beiles $B$, Björck $M, H a l-$

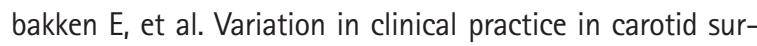
gery in nine countries 2005-2010. Lessons from VASCUNET and recommendations for the future of national clinical audit. Eur J Vasc Endovasc Surg 2012;44:11-17.

4. Eckstein $H H$, Reiff $T$, Ringleb $P$, Jansen 0 , Mansmann $U_{\text {, }}$ Hacke $W$, et al. SPACE-2: a missed opportunity to compare carotid endarterectomy, carotid stenting, and best medical treatment in patients with asymptomatic carotid stenoses. Eur J Vasc Endovasc Surg 2016;51:761-765.

5. Naylor AR, Ricco JB, de Borst GJ, Debus S, de Haro J, Halliday $A$, et al. Editor's choice-management of atherosclerotic carotid and vertebral artery disease: 2017 clinical practice guidelines of the European Society for Vascular Surgery (ESVS). Eur J Vasc Endovasc Surg 2018;55:3-81.

6. Kamtchum-Tatuene J, Noubiap JJ, Wilman AH, Saqqur M,
Shuaib A, Jickling GC. Prevalence of high-risk plaques and risk of stroke in patients with asymptomatic carotid stenosis: a meta-analysis. JAMA Neurol 2020;77:1524-1535.

7. De Rango P, Brown MM, Leys D, Didier L, Howard VJ, Moore WS, et al. Management of carotid stenosis in women: consensus document. Neurology 2013;80:2258-2268.

8. Paraskevas $\mathrm{KI}$, Mikhailidis DP, Antignani $\mathrm{PL}$, Baradaran $\mathrm{H}_{\text {, }}$ Bokkers RPH, Cambria RP, et al. Optimal management of asymptomatic carotid stenosis in 2021: the jury is still out. An International, Multispecialty, Expert Review and Position Statement. J Stroke Cerebrovasc Dis 2021;31:106182.

9. AbuRahma AF, Avgerinos ED, Chang RW, Darling RC 3rd, Duncan $A A$, Forbes $T L$, et al. Society for vascular surgery clinical practice guidelines for management of extracranial cerebrovascular disease. J Vasc Surg 2022;75(1S):4S-22S.

10. Liapis CD, Eckstein HH, Paraskevas KI, Cronenwett JL. Emerging evidence suggests that patients with high-grade asymptomatic carotid stenosis should be revascularized. J Vasc Surg 2022;75(1S):23S-25S.

Correspondence: Kosmas I. Paraskevas

Department of Vascular Surgery, Central Clinic of Athens, 24, Alexander Papagou Street, N. Iraklio 14122, Athens, Greece

Tel: $+30-698-3133883$

Fax: +30-210-3215792

E-mail: paraskevask@hotmail.com

https://orcid.org/0000-0001-6865-2919

Received: December 28, 2021

Revised: December 28, 2021

Accepted: December 31, 2021

The authors have no financial conflicts of interest. 